TAPROBANICA, ISSN 1800-427X. May, 2020. Vol. 09, No. 01: pp. 12-22, pls. 4-8. (C) Research Center for Climate Change, University of Indonesia, Depok, Indonesia www.taprobanica.org

\title{
A REVISION OF Eutropis rudis (BOULENGER, 1887), RESURRECTION OF E. lewisi (BARTLETT, 1895) AND DESCRIPTION OF A NEW SPECIES (REPTILIA: SCINCIDAE) FROM GREAT NICOBAR
}

\section{A.A. Thasun Amarasinghe ${ }^{1,7}$, S.R. Chandramouli ${ }^{2}$, Kaushik Deuti ${ }^{3}$, Patrick D. Campbell ${ }^{4}$, Sujan M. Henkanaththegedara ${ }^{5} \&$ Suranjan Karunarathna ${ }^{6}$}

${ }^{1}$ Research Center for Climate Change, University of Indonesia, Gd. PAU Lt. 8.5, Kampus UI, Depok 16424, Indonesia

${ }^{2}$ Department of Ecology and Environmental Sciences, School of Life Sciences, Pondicherry University, Puducherry, India

${ }^{3}$ Zoological Survey of India, Herpetology Division, 27, Jawaharlal Nehru Road, Kolkata 700016, India

${ }^{4}$ Department of Life Sciences, Darwin Centre, Natural History Museum, Cromwell Road, South Kensington, London SW7 5BD, England

${ }^{5}$ Biological \& Environmental Sciences, Longwood University, Farmville, VA 23909, USA

${ }^{6}$ Nature Explorations \& Education Team, No: B-1 / G-6, De Soysapura Flats, Moratuwa 10400, Sri Lanka

${ }^{7}$ Association of Asian Herpetology (Asosiasi Herpetologi Asia), Jl. BSD Bintaro No. 88, Pondok Aren 15228, Tangerang Selatan, Indonesia

${ }^{1}$ Corresponding author. E-mail: thasun@rccc.ui.ac.id

\begin{abstract}
We examined the syntype series of Eutropis rudis (6 specimens) collected from Sumatra and Borneo, currently deposited at the Natural History Museum, London. We observed that the type series is composed of two species. In order to stabilize application of the name, we designate a lectotype for $E$. rudis from Sumatra. Mabuya lewisi, described based on a specimen from Borneo, is resurrected as a valid species of Eutropis and redescribed. Based on morphology and geographic distribution, we describe a new species of this complex from Great Nicobar Island with two specimens deposited at the Zoological Survey of India (ZSI), Kolkata.
\end{abstract}

Key words: Borneo, Great Channel, lectotype, Mabuya, Sumatra, systematic, taxonomy.

\section{Introduction}

The tricarinate skink Mabuia rudis was described by Boulenger (1887) based on six specimens collected from Sumatra (one specimen) and Borneo (five specimens). Later, Bartlett (1895) described Mabuia lewisi from
North Borneo, based on at least two specimens. He named another variation of $M$. rudis, as var. kuchingensis from Kuching, Borneo. Smith (1935) synonymised Bartlett's species and the variants with $M$. multifasciata (Kuhl, 1820). At the same time, Smith (1935) reduced M. rudis to 
a subspecies of $M$. multifasciata, despite the cooccurrence of both taxa on a number of islands. Brown \& Alcala (1980) regarded M. rudis as a full species again. Subsequently, Mausfeld \& Böhme (2002) described Mabuya macrophthalma from Sulawesi (type locality: Java in error; see Amarasinghe et al. 2018). Afterwards Howard et al. (2007) described Eutropis grandis from Sulawesi, a species which was synonymised with Eutropis macrophthalma by Amarasinghe et al. (2018).

Currently, the Eutropis multifasciata complex consists of three recognised taxa [fide Amarasinghe et al. 2017: 105-106, 2018): E. multifasciata (Kuhl, 1820), E. rudis (Boulenger, 1887 ) and E. macrophthalma (Mausfeld \& Böhme, 2002). In this study we examined the type material (including synonym types) and several other voucher specimens of $E$. rudis in several museums. In the collections of the Zoological Survey of India, Kolkata (ZSI) we found two Eutropis specimens collected from Great Nicobar (ZSI 23483, 25118) identified as E. rudis, but differing in several respects. These are described here as new species. Examination of the extant $M$. lewisi (presently a synonym of E. rudis) syntype revealed clear differences from the specimens of $M$. rudis s. str., and we regard the differences to be distinct enough to consider it a valid species of the genus Eutropis.

\section{Material and methods}

We compared specimens (including types), original descriptions, and synonymised species types of the Eutropis rudis complex (Appendix I). Museum acronyms are those of Uetz et al. (2019). We examined the external morphology of specimens by using a Wild M3Z stereomicroscope. Sex was not determined from specimens unless the hemipenes in males were everted. All locality records are based on our personal observations and data recorded in museums. Altitudes are given in metres above mean sea level. The following measurements were taken to the nearest $0.1 \mathrm{~mm}$ on the left side of the body with a Mitutoyo digital caliper: snout-vent length (SVL, from tip of snout to anterior margin of vent), head length (HL, from posterior edge of the retro-articular process of the mandible to tip of snout), head width (HW, width of head at the temporo-mandibular articulation / angle of the jaws), snout length (ES, from anterior border of orbit to tip of snout), eye-nostril length (EN, from anterior border of orbit to the posterior border of nostril), orbit diameter (ED, the greatest horizontal diameter of the orbit), tympanum-eye length (TYE, from posterior border of orbit to anterior border of tympanum), thigh length (FEL, from the anterior margin of the hind limb at its insertion point on the body to the knee while flexed 90 degree), shank length (TBL, from the posterior surface of the knee while flexed 90 degree to the base of the heel), and toe lengths (from tip of finger, to the junction with the adjacent digit, excluding the claw). Supralabial and infralabial scales were counted from the gape of the lips to the rostral and mental scales respectively. Ventrals included all scales from the scale posterior to the postmental to the last scale bordering the vent, counted along the ventral midline. Paravertebral scales are between postparietal / nuchal (included) to the level of the posterior margin of the thigh in a straight line immediately left of the vertebral column. Subdigital lamellae on toe IV from the first proximal enlarged lamellae wider than the width of the largest palm scale to the distal-most lamella at the base of the claw. Total number of longitudinal scale rows was counted around the midbody.

We conducted both univariate and multivariate analyses on three morphometric ratios (TYE/SVL, ED/SVL and TBL/SVL) covering keel-scaled skinks of the E. rudis complex: Eutropis rudis and E. lewisi from Borneo, E. macrophthalma from Sulawesi, and the new species from Great Nicobar, to explore morphometric differences among putative species. We excluded the smooth-scaled $E$. multifasciata from our comparisons. The univariate analyses for each ratio were conducted by separate one-way ANOVAs considering morphometric ratio as the response variable and the species as the predictor variable. Post-hoc analyses were conducted by performing a Tukey HSD test when necessary. Multivariate analyses were conducted using Nonmetric multidimensional scaling (NMDS) to reduce the morphometric ratio matrix of seven to two dimensions using the metaMDS function in the R package "vegan" (Oksanen et al. 2012). The ordination was based on a Bray-Curtis distance measure. The ordination plot was based on the Pearson Correlation Coefficient for each ratio against the two NMDS axes. We considered stress less than 0.20 as an adequate solution (McCune \& Grace 2002). All statistical analyses were conducted using the $\mathrm{R}$ statistical software program. 


\section{Results}

The syntype series of Mabuia rudis (BMNH 1946.8.15.26, 1946.9.7.46-50) is composed of two morphospecies originating from the islands of Sumatra and Borneo. In order to stabilize the name with a recognized type specimen and to solve the complex taxonomic problem, it is essential to designate a lectotype. Although Boulenger (1887) examined six specimens (one adult and five juveniles) for his original description, he provided the measurement for only the adult (largest specimen) he had at hand, which was collected from Sumatra. Therefore, we designate that specimen, BMNH 1946.8.15.26 as the lectotype of Mabuia rudis. One of the Bornean paralectotypes of $M$. rudis, BMNH 1946.9.7.46 is clearly identified, following examination, as Eutropis rudis.

Mabuia lewisi (Bartlett, 1895) has been considered a junior subjective synonym of Mabuia rudis since Smith (1935). However a critical comparison of the designated lectotype of Mabuia rudis and the available type specimen of Mabuia lewisi at BMNH revealed that the latter is morphologically distinct enough to be regarded as a separate species. Therefore we recognise and redescribe Mabuia lewisi as a valid species of the genus Eutropis. The number of specimens comprising the syntype series of Mabuia lewisi is unclear, though the original description implies the possibility of having at least two specimens because the author described the morphology of both sexes. Therefore, in order to stabilize the name with a recognized type specimen and to solve the complex taxonomical problem, we hereby designate the available type specimen BMNH 1946.8.3.57 as the lectotype. The paralectotypes of Mabuia rudis, BMNH 1946.9.7.47-50 also represent Eutropis lewisi. Furthermore, the original description of Mabuia rudis and Mabuia lewisi were very concise, lacking most of the important diagnostic characters, so here we provide comprehensive redescriptions based on their lectotypes. We present diagnostic morphological, morphometric, and meristic data taken from the type specimens and other specimens examined (Tables 1-3).

Table 1. Mean differences of morphometric ratios of E. rudis, E. lewisi, E. macrophthalma, and the new species. Only significant $p$-values are shown for Tukey HSD pairwise comparisons. Post hoc analysis (Tukey HSD) significance level $0.05(p<0.05)$.

\begin{tabular}{|c|c|c|c|c|c|c|c|c|}
\hline \multirow[b]{2}{*}{$\begin{array}{l}\text { Taxonomic } \\
\text { ratio }\end{array}$} & \multirow[b]{2}{*}{$F$ value } & \multirow[b]{2}{*}{$p$ value } & \multicolumn{6}{|c|}{ Tukey HSD } \\
\hline & & & 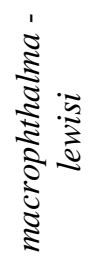 & 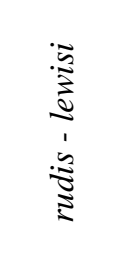 & $\begin{array}{l}\cdot \tilde{5} \\
3 \\
0 \\
0 \\
1 \\
\tilde{3} \\
0 \\
\vdots \\
0 \\
0 \\
0\end{array}$ & 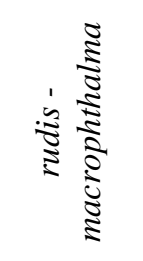 & 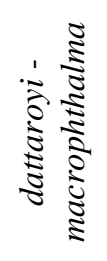 & 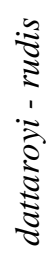 \\
\hline HL/SVL & 2.31 & $>0.05$ & & & & & & \\
\hline HW/SVL & 2.31 & $>0.06$ & & & & & & \\
\hline ES/SVL & 1.18 & $>0.07$ & & & & & & \\
\hline TYE/SVL & 10.08 & $<0.001$ & & $<0.01$ & $<0.01$ & $<0.01$ & $<0.01$ & \\
\hline ED/SVL & 4.13 & $<0.05$ & & & & & & \\
\hline TBL/SVL & 10.28 & $<0.0001$ & & $<0.001$ & & $<0.0001$ & & \\
\hline FEL/SVL & 1.26 & $>0.05$ & & & & & & \\
\hline
\end{tabular}

Three morphometric ratio mean comparisons (TYE/SVL, ED/SVL and TBL/SVL) showed significant mean differences between the four species (Fig. 1, Table 1). However, posthoc pairwise comparisons did not generate significant results for ED/SVL. There are significant morphometric differences between $E$. rudis, E. lewisi and E. macrophthalma in TYE/SVL and TBL/SVL. This suggests that the tympanum-eye distance of $E$. rudis is significantly greater than that of both E. lewisi and $E$. macrophthalma. Shank lengths of both $E$. lewisi and E. macrophthalma are significantly greater than that of $E$. rudis, suggesting relatively shorter hind limbs in E. rudis. The Great Nicobar specimens are easily separated from E. lewisi and E. macrophthalma by the significantly longer distance of the tympanumeye, and also easily separated from $E$. rudis by its significantly longer snout. NMDS achieved an adequate two-dimensional solution for the above Eutropis species (Fig. 2; stress $=0.072$ ). 
It generated four distinct clusters which corresponded with the four Eutropis species and may indicate taxonomic distance of E. rudis + the new species from Great Nicobar, and $E$. lewisi + E. macrophthalma (Fig. 2). These close morphometric similarities between the Great Nicobar population and $E$. rudis, combined with the relative distribution of four species may indicate a potentially closer relationship of the new species from Great Nicobar with $E$. rudis than E. lewisi and E. macrophthalma. However considering several other diagnostic meristic characters, Great Nicobar specimens are completely distinct from E. rudis, therefore a new species name is assigned herein.

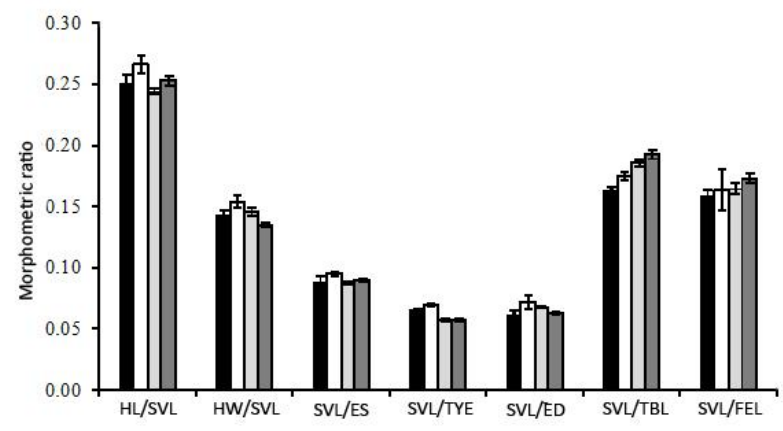

Figure 1. Mean differences of seven morphometric ratios of Eutropis rudis from Borneo (black), E. macrophthalma from Sulawesi (dark grey), E. lewisi from Borneo (light grey), and the new species from Great Nicobar (white).

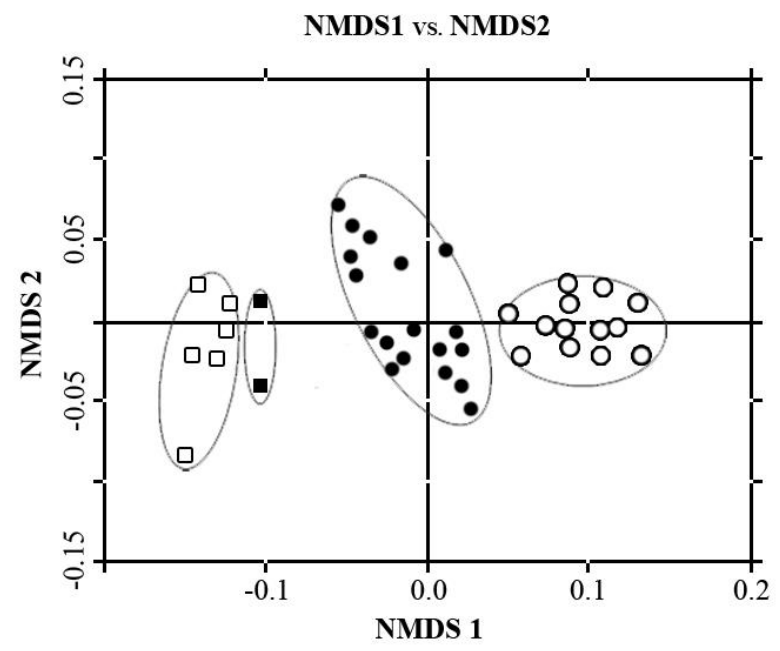

Figure 2. NMDS ordination plot of morphometric variation in Eutropis rudis (open squares), E. macrophthalma (open circles), E. lewisi (closed circles), and the new species (closed squares). (Stress $=0.072$ ); each point represents an individual specimen; and the relative distances between two points represents the similarity (or dissimilarity).

\section{Taxonomy}

Eutropis rudis (Boulenger, 1887)

(Figs. 1-3, 4a, 7-9; Tables 1-3)

Mabuia rudis Boulenger, 1887

Lectotype (designated herein). Adult male, BMNH 1946.8.15.26 (previously 1879.9.17.1, mistakenly written as 1879.9.17.2 in 1946 register), SVL $104.0 \mathrm{~mm}$, collected from Padang, West Sumatra, Indonesia [see discussion], by Karl Bock and purchased from E. Gerrard.

Other specimens $(\boldsymbol{n}=\mathbf{1 2}) . \quad \mathrm{BMNH}$ 1946.9.7.46 (paralectotype of Mabuia rudis), collected from Matang, Sarawak, Borneo, purchased from Mr. Cutter [most probably William George Cutter]; ZSI 15330, 15332, 15344-45, 20323 collected from Sarawak, Borneo; ZSI 2307, 12680, 12735, 13474, 24795 collected from Myanmar; ZSI 18071 collected from Thailand.

Diagnosis. $E$. rudis is diagnosed by the following combination of morphological characters: moderate body size (SVL 66.7-123.1 $\mathrm{mm}$ ); tricarinate dorsal scales; scaly lower eyelid; 42-46 paravertebrals; 55-59 ventrals; 18-20 subdigital lamellae under toe IV; 32-34 midbody scale rows; temporals and scales on dorsal surface of the thigh keeled; supraoculars I and II in contact with the frontal and the presence of distinct, dark lateral bands along the body.

Description of lectotype. Male, SVL $104.0 \mathrm{~mm}$. Head moderately large (HL $23.1 \%$ of SVL, HL $46.9 \%$ of AG), narrow (HW $66.6 \%$ of HL, HW $15.4 \%$ of SVL), indistinct from neck; snout short (ES $39.2 \%$ of HL, ES $58.7 \%$ of HW), slightly convex in lateral profile; rostral shield large, hemispherical, slightly visible from above, posterior margin of midpoint curved; frontonasal slightly in contact with rostral; frontonasal wide, lateral border touching first loreal; prefrontals widely in contact separating the frontal and frontonasal, largest distance along the longitudinal axis of frontonasal equal to the prefrontals in length, lower border touching both loreal scales, the posterior border touching the first supraocular, and frontal; frontal large, elongate, subtriangular, bluntly pointed posteriorly, equal in length to the frontoparietals and interparietal combined; frontoparietals two, in contact, distinct, slightly larger than interparietal; parietals large and completely separated by interparietal, touching pretemporal 


\section{Plate 04}

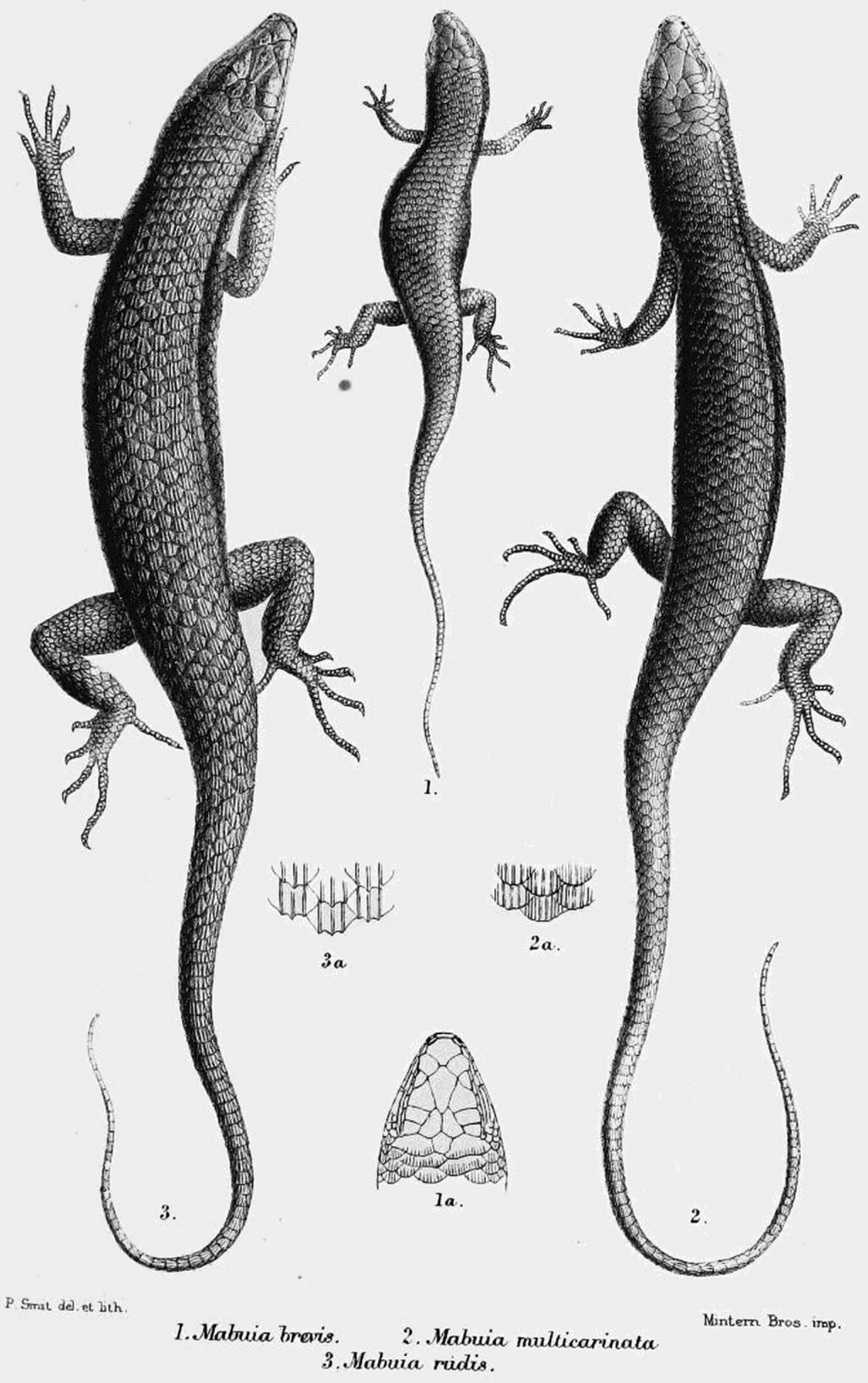

Figure 3. The original figure of Eutropis rudis illustrated in the original description; reprinted from Boulenger, 1887 [Catalogue of the Lizards in the British Museum (Nat. Hist.) III, London: pl. XI]. (C) The Trustees of the Natural History Museum, London, UK. 


\section{Plate 05}
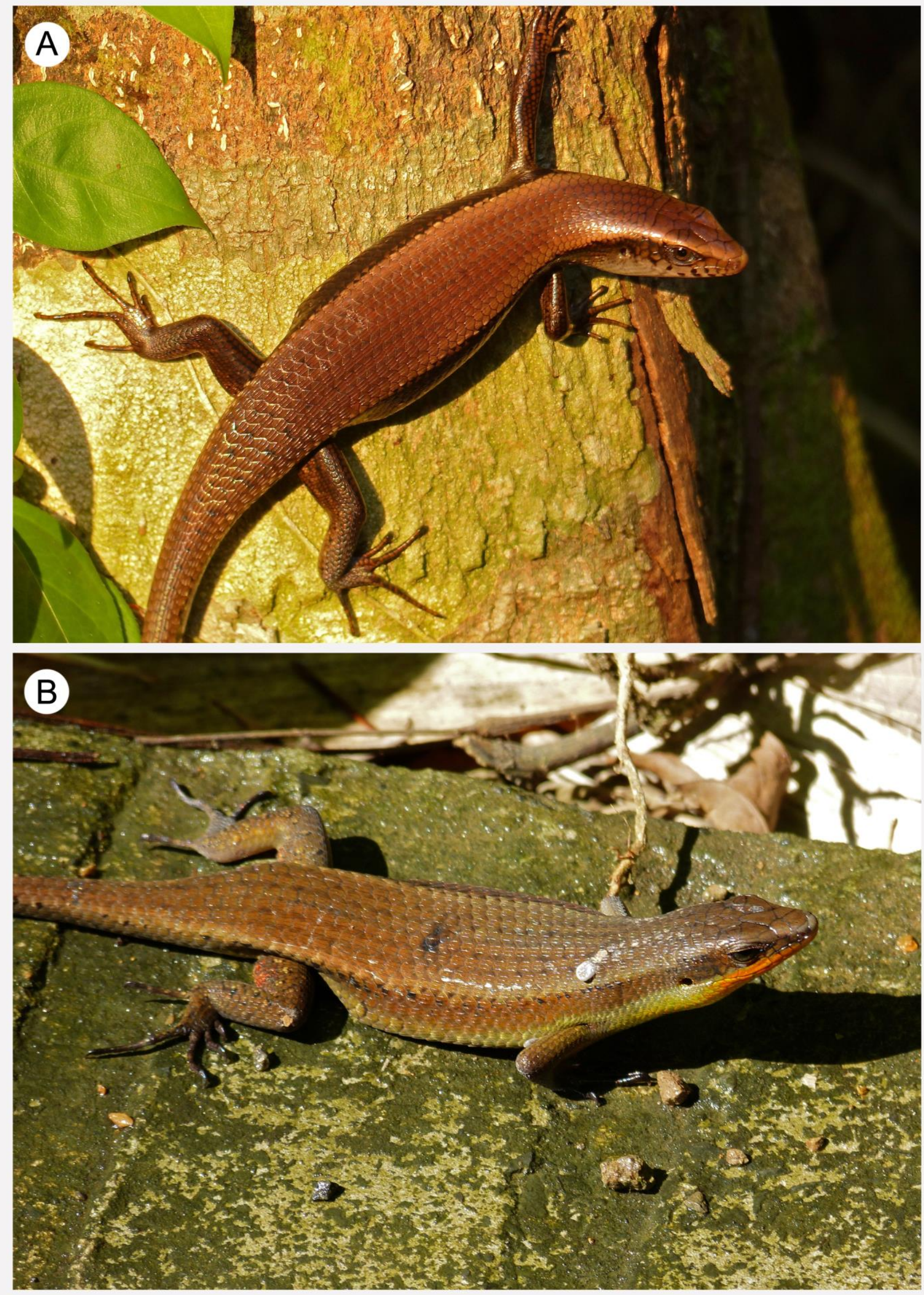

Figure 4. (A) Eutropis rudis from Santubong Peninsula, Kuching, Sarawak, Malaysia; (B) Eutropis lewisi from Sepilok, Sabah, Malaysia (not collected). Photographs (C) Bernard Dupont 
scales laterally; nuchals single pair, overlapping mid-dorsally behind interparietal. Nostril large and placed in the middle of nasal; single supranasal; loreals two, anterior loreal touching nasal, supranasal, frontonasal, prefrontal, posterior loreal, and $2^{\text {nd }}$ and $3^{\text {rd }}$ supralabials; posterior loreal longer than the anterior loreal in the longitudinal axis, touching prefrontal and first supraciliary; two presuboculars; eye large (ED $18.7 \%$ of HL), orbit diameter smaller than tympanum-eye length, pupil rounded; interorbital distance broad; three small postoculars; supraoculars wide, four, second is the longest in the longitudinal axis and the widest in the transverse axis and fully contacts the frontal; first supraocular in contact with prefrontal and frontal, $2^{\text {nd }}$ in contact with frontal, $3^{\text {rd }}$ in contact with frontoparietals, and $4^{\text {th }}$ in contact with both frontoparietal and parietal; supraciliaries five; eyelid moveable, scaly window separated into several scales. Six supralabials, fifth largest and at the mid orbit position $\left(5^{\text {th }}\right.$ and $6^{\text {th }}$ touching orbit $)$; three pretemporals; three primary temporals, three secondary temporals; infralabials five; ear opening deep, small, near spherical and approximately one quarter of eye diameter. Mental large; a single large postmental followed by two chin shield pairs, the first pair meeting in midline, the first chin shield in contact with first and second infralabial scales, the second pair in contact with second and third infralabials.

With the exception of head shields and nuchals pair all body scales are tricarinate; all scales imbricate and lack apical pits; scales on the dorsal surface of thigh moderately tricarinate; body slender, elongate (AG $49.2 \%$ of SVL); midbody scale rows 33; paravertebral scales 45 ; five enlarged preanal scales.

Forelimbs short, hind limbs relatively long (FEL $15.8 \%$ of SVL, TBL $15.2 \%$ of SVL); shank slightly short and $96.3 \%$ of thigh length; dorsal surfaces of fore and hind limbs moderately carinate; subdigital lamellae on toes I, 9; II, 12; III, 16; IV, 19; and V, 12; relative length of digits those of fingers: IV $>$ III $>$ II $>$ V > I; those of toes: IV > III $>$ V $>$ II $>$ I. Tail complete, median scale row of subcaudals of original tail subequal with the scales beside.

Variation. See Table 2.

Coloration. Dorsal head and body light copper brown, limbs more reddish dorsally; brown untidy band commencing from posterior eye passing through tympanum until shoulder, bordered above by a white stripe. Venter white.
Eutropis lewisi (Bartlett, 1895) comb. nov.

(Figs. 1, 2, 4b, 7-9; Tables 1-3)

Mabuia rudis Boulenger, 1887 [Partim: BMNH 1946.9.7.47-50]

Mabuia lewisi Bartlett, 1895

Lectotype (designated herein). Adult male, BMNH 1946.8.3.57 (previously 1899.1.20.3), SVL $90.1 \mathrm{~mm}$, collected from Kuching [Santubong at elevation $60 \mathrm{~m}$ a.s.l. fide Bartlett (1895)], Sarawak, North Borneo, received from the Sarawak Museum.

Other specimens $(\boldsymbol{n}=\mathbf{2 4}) . \quad \mathrm{BMNH}$ 1946.9.7.47-50 (paralectotype of Mabuia rudis) collected from Matang, Sarawak, Borneo, purchased from Mr. Cutter [probably William George Cutter]; MZB 2937, 9521-23, 13224, 13227, 13228, 13231, 13232, 13236-39 collected from Kalimantan, Indonesia; ZSI 15155, 15160-62, 15328, 15346, 20323 collected from Sarawak Borneo.

Diagnosis. E. lewisi is diagnosed by the following combination of morphological characters: moderate but relatively smaller body size (SVL 71.2-98.6 mm); tricarinate dorsal scales; scaly lower eyelid; 32-35 paravertebrals; 48-52 ventrals; 19-21 subdigital lamellae under toe IV; 28-30 midbody scale rows; temporals and scales on dorsal surface of the thigh keeled; only the supraocular II in contact with the frontal and the absence of distinct, dark lateral bands along the body.

Description of lectotype. Male, SVL $90.1 \mathrm{~mm}$. Head moderately large (HL $24.4 \%$ of SVL, HL $46.5 \%$ of AG), narrow (HW $71.8 \%$ of HL, HW $17.5 \%$ of SVL), indistinct from neck; snout short (ES $37.3 \%$ of HL, ES $51.9 \%$ of HW), slightly convex in lateral profile; rostral shield large, hemispherical, distinctly visible from above, posterior margin of midpoint curved; frontonasal in contact with rostral; frontonasal wide, lateral border touching first loreal; prefrontals widely in contact separating the frontal and frontonasal, largest distance along the longitudinal axis of frontonasal longer than length of prefrontals, lower border touching both loreal scales, the posterior border touching the first supraocular, and frontal; frontal large, elongate, subtriangular, bluntly pointed posteriorly, equal in length to frontoparietals and interparietal combined; frontoparietals two, in contact, distinct, larger than interparietal; parietals large and completely separated by 
interparietal, touching pretemporal scales laterally; nuchals single pair, overlapping middorsally behind interparietal. Nostril large and placed in the middle of nasal; single supranasal; loreals two, anterior loreal touching nasal, supranasal, frontonasal, prefrontal, posterior loreal, and $2^{\text {nd }}$ supralabial; posterior loreal longer than the anterior loreal in the longitudinal axis, touching prefrontal and first supraciliary; two presuboculars; eye large (ED 24.1\% of HL), orbit diameter and the tympanum-eye length equal in length, pupil rounded; interorbital distance broad; three small postoculars; supraoculars wide, four, second is the longest in the longitudinal axis and the widest in the transverse axis and fully contacts the frontal; first supraocular in contact with prefrontal and not in contact with frontal, $2^{\text {nd }}$ in contact with frontal and frontoparietal, $3^{\text {rd }}$ in contact with frontoparietal, and $4^{\text {th }}$ in contact with both frontoparietal and parietal; supraciliaries six; eyelid moveable, scaly window separated into several scales.

Six supralabials, fifth largest and at the mid orbit position $\left(5^{\text {th }}\right.$ touching orbit); three pretemporals; three primary temporals, three secondary temporals; infralabials five; ear opening deep, small, near spherical and approximately one quarter of eye diameter. Mental large; a single large postmental followed by two chin shield pairs, the first pair meeting in midline, the first chin shield in contact with first and second infralabial scales, the second pair in contact with second and third infralabials.

With the inclusion of head shields and nuchals pair all body scales are strongly carinate, body scales tricarinate; all scales imbricate and lack apical pits; scales on the dorsal surface of thigh strongly tricarinate; body slender, elongate (AG 52.5\% of SVL); midbody scale rows 28; paravertebral scales 33; five enlarged preanal scales.

Forelimbs short, hind limbs relatively long (FEL $19.2 \%$ of SVL, TBL $17.1 \%$ of SVL); shank short and $89.0 \%$ of thigh length; dorsal surfaces of fore and hind limbs strongly carinate; subdigital lamellae on toes I, 7; II, 11; III, 17; IV, 20; and V, 13; relative length of digits those of fingers: IV $>$ III $>$ II $>$ V $>$ I; those of toes: IV $>$ III $>$ V > II > I. Tail complete, median scale row of subcaudals of original tail subequal.

Variation. See Table 2.

Coloration. Dorsal head, body and limbs uniform dark copper brown. Venter white, throat greyish.
Eutropis dattaroyi sp. nov.

(Figs. 1, 2, 5-9; Tables 1-3)

Mabuya rudis — Biswas \& Sanyal 1980; Biswas 1984; Das 1994; Das 1999; Vijayakumar 2005 [Partim]

Holotype. Adult male, ZSI 25118, SVL 123.1 $\mathrm{mm}$, collected from Joginder Nagar $(24 \mathrm{~km}$ post of S.N.S. Road), South of Campbell Bay, Great Nicobar Island, by Dr. K.K. Tiwari (during Andaman \& Nicobar Survey - 1977) on 29 March 1977.

Paratype $(\boldsymbol{n}=\mathbf{1})$. Adult male, ZSI 23483, SVL $99.3 \mathrm{~mm}$, other details are the same as holotype. See Table 2 for morphometric and meristic characters, other morphological characters is same as holotype.

Diagnosis. E. dattaroyi sp. nov. is diagnosed by the following combination of morphological characters: moderate body size (SVL 99.3-123.1 $\mathrm{mm}$ ); tricarinate dorsal scales; scaly lower eyelid; 52-53 paravertebrals; 65-70 ventrals; 20-21 subdigital lamellae under toe IV; 36-38 midbody scale rows; temporals smooth; scales on dorsal surface of the thigh keeled; only the supraocular II in contact with the frontal and the absence of dark lateral or longitudinal bands along the body (Table 3 ).

Description of holotype. Male, SVL $123.1 \mathrm{~mm}$. Head moderately large (HL 25.9\% of SVL), narrow (HW $61.1 \%$ of HL, HW $15.8 \%$ of SVL), indistinct from neck; snout short (ES 36.0\% of HL, ES $59.0 \%$ of HW), slightly concave in lateral profile; rostral shield large, hemispherical, visible from above, posterior margin of midpoint concave; frontonasal in broad contact with rostral; frontonasal wide, lateral border touching first loreal; prefrontals in broad contact, separating frontal and frontonasal, length equals maximum frontonasal length, laterally contacting both loreal scales, posterior border contacting first supraciliary, first two supraoculars and frontal; frontal large, elongate, subtriangular, bluntly pointed posteriorly, length equal to frontoparietals and interparietal combined; frontoparietals two, in contact, larger than interparietal; parietals large and completely separated by interparietal, contacting pretemporal scales anterolaterally; single pair of nuchals, overlapping mid-dorsally behind interparietal. Nostril large and placed in centre of nasal; supranasal single; loreals two, anterior contacting nasal, supranasal, frontonasal, 


\section{Plate 06}
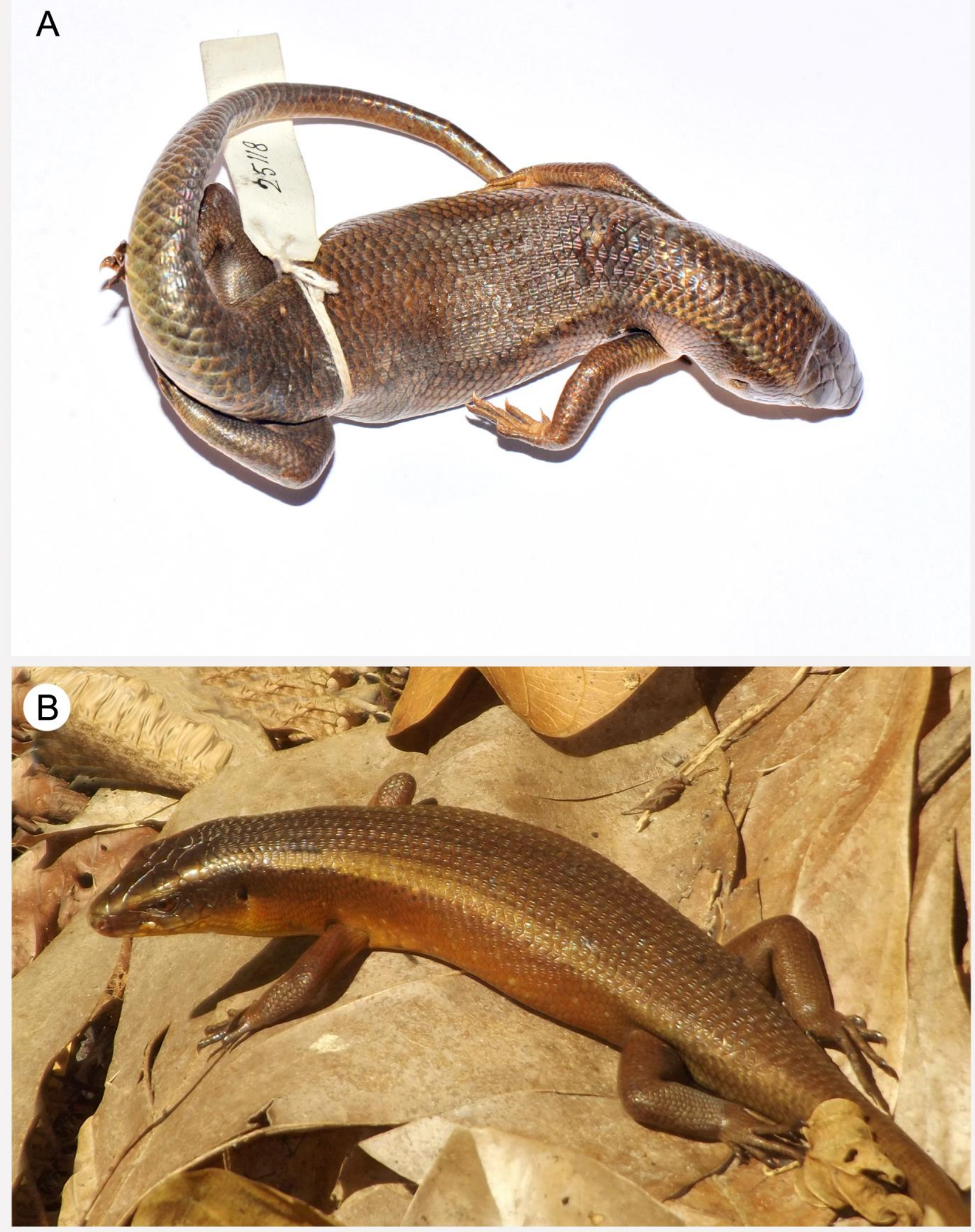

Figure 5. Eutropis dattaroyi sp. nov. (A) holotype (ZSI 25118) from Joginder Nagar (24 km post of S.N.S. Rd.), South of Campbell Bay, Great Nicobar Island. Photograph (C) A.A.T. Amarasinghe; (B) an adult live specimen from Great Nicobar (not collected). Photograph (C) S.R. Chandramouli 
prefrontal, posterior loreal, and first two supralabials; posterior longer than anterior loreal in the longitudinal axis, contacting prefrontal, first supraciliary, and third supralabial; presuboculars two; eye large (ED 25.7\% of HL; slightly smaller than TYE), pupil rounded; interorbital distance broad; postoculars three, small; supraoculars four, all wide, second longest in the longitudinal axis and widest in the transverse axis, $1^{\text {st }}$ supraocular in contact with prefrontal, $2^{\text {nd }}$ in contact with prefrontal, frontal, and frontoparietal, $3^{\text {rd }}$ in contact with frontoparietal, $4^{\text {th }}$ in contact with frontoparietal and parietal; supraciliaries seven; eyelid moveable, window divided into several tall rectangular scales. Supralabials six, fifth largest, at the mid orbit position, and contacting granular scales of lower eyelid; pretemporals three; primary temporals three, secondary temporals three; infralabials six; ear opening small (approximately one quarter ED), deep, near round. Mental large; postmental single, large; two pairs of chin shields, first pair meeting in midline, first chin shield in contact with first and second infralabial scales, the second pair in contact with second and third infralabials.

With the exception of head shields and nuchals, all dorsal scales are tricarinate; all scales imbricate; scales on dorsal surface of thigh moderately tricarinate; body slender, elongate; midbody scale rows 38; paravertebral scales 53; ventrals 70; preanal scales enlarged, five.

Forelimbs short, hind limbs relatively long (FEL $14.7 \%$ of SVL, TBL $17.2 \%$ of SVL); thigh shorter (FEL $85.4 \%$ of TBL); dorsal surfaces of fore and hind limbs moderately tricarinate; subdigital lamellae of toes I-V, 7, 12, 17, 20 and 12 respectively; relative length of fingers IV > III > II > V > I; those of toes IV > III > V > II > I. Tail complete, median scale row of subcaudals of original tail entire.

Variation. See Table 2.

Coloration. Dorsal head, body and limbs light uniform copper brown, limbs darker. Venter cream.

Etymology. The specific epithet is an eponym latinised as a noun in the genitive singular, honouring Dr. Aniruddha Datta-Roy for his remarkable contributions to the field of herpetology, especially on skinks (Reptilia: Scincidae) of the Indian subcontinent. Aniruddha Datta-Roy is an Indian herpetologist, and the sectional editor for skinks of the journal Zootaxa.
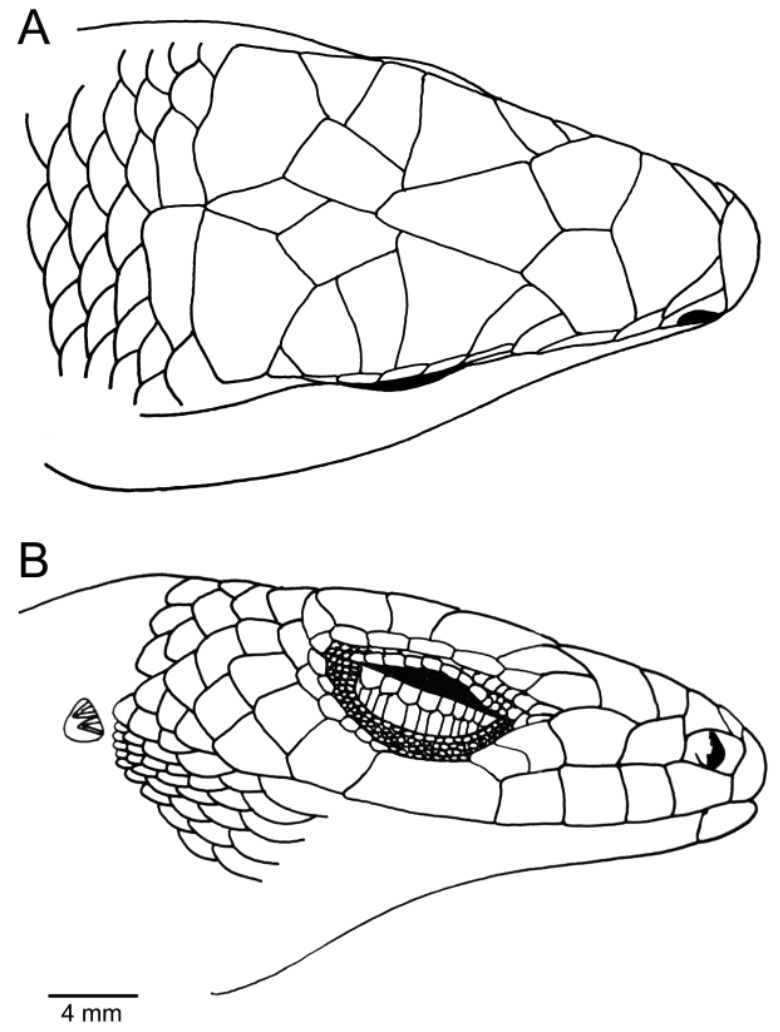

Figure 6. Head in (A) dorsal and (B) lateral views of the holotype of Eutropis dattaroyi sp. nov. (ZSI 25118). Illustration (C A.A.T. Amarasinghe

Comparison. Comparisons between Eutropis dattaroyi sp. nov. and putative closely related congeners (E. lewisi, E. macrophthalma, E. multifasciata, E. rudis) are presented in Table 2. Unlike the new species, which is tricarinate, E. dissimilis (Hallowell, 1857) has bicarinate dorsal scales; E. quadricarinata (Boulenger, 1887) has quadricarinate dorsal scales; $E$. andamanensis (Smith, 1935), E. carinata (Schneider, 1801), E. gansi (Das, 1991), E. madaraszi (Méhely, 1897), E. multicarinata (Gray, 1845), E. rugifera (Stoliczka, 1870), and E. trivittata (Hardwicke \& Gray, 1827) have quinquecarinate dorsal scales; $E$. macularia (Blyth, 1853) and E. tammanna Das, de Silva \& Austin, 2008 have six dorsal scale keels.

Eutropis beddomii (Jerdon, 1870) has 12-16 lamellae under the fourth toe, E. floweri (Taylor, 1950) has 15-16 lamellae, E. tytleri (Theobald, 1868) has 28 lamellae, E. ashwamedhi (Sharma, 1969) has 13-15 lamellae (vs 20 or 21 in $E$. dattaroyi sp. nov.). Eutropis bibronii (Gray, 1839), E. innotata (Blanford, 1870), E. nagarjunensis (Sharma, 1969), and $E$. quadratilobus (Bauer \& Günther, 1992) have a transparent lower eyelid disc ( $v s$ scaly in $E$. dattaroyi sp. nov.). Eutropis clivicola (Inger, 
Shaffer, Koshy et al., 1984) has 46 ventrals (vs 65-70 in E. dattaroyi sp. nov.). E. allapallensis (Schmidt, 1926) has a single frontoparietal (vs 2 in $E$. dattaroyi sp. nov.). E. longicaudata (Hallowell, 1857) has 26-30 midbody scale rows (vs 36-38 midbody scale rows in $E$. dattaroyi sp. nov.). E. austini Batuwita, 2016 and E. greeri Batuwita, 2016 have 31-39 paravertebral scales (vs 52-53 in E. dattaroyi sp. nov.).

Table 2. Morphometric (in $\mathrm{mm}$ ) and meristric character comparisons of Mabuia rudis Boulenger, 1887 lectotype; M. lewisi Bartlett, 1895 holotype, Eutropis dattaroyi sp. nov. holotype and paratype, and other specimens; "_" = not measured.

\begin{tabular}{|c|c|c|c|c|c|c|}
\hline & \multicolumn{2}{|c|}{ E. rudis } & \multicolumn{2}{|c|}{ E. lewisi } & \multicolumn{2}{|c|}{ E. dattaroyi sp. nov. } \\
\hline & $\begin{array}{c}\text { Lectotype } \\
\text { (BMNH } \\
\text { 1946.8.15.26) }\end{array}$ & $\begin{array}{l}\text { Other } \\
(n=12)\end{array}$ & $\begin{array}{c}\text { Holotype } \\
\text { (BMNH } \\
1946.8 .3 .57)\end{array}$ & $\begin{array}{l}\text { Other } \\
(n=24)\end{array}$ & $\begin{array}{c}\text { Holotype } \\
\text { (ZSI } \\
25118) \\
\end{array}$ & $\begin{array}{c}\text { Paratype } \\
\text { (ZSI } \\
23483) \\
\end{array}$ \\
\hline locality & Sumatra & $\begin{array}{l}\text { Borneo, } \\
\text { Thailand, } \\
\text { Myanmar }\end{array}$ & Borneo & Borneo & Nicobar & Nicobar \\
\hline Sex & Male & both & Male & both & Male & Male \\
\hline SVL & 104.0 & $66.7-123.1$ & 90.1 & 71.2-98.6 & 123.1 & 99.3 \\
\hline Head length (HL) & 24.0 & $18.2-31.9$ & 22.0 & $17.0-25.6$ & 31.9 & 27.2 \\
\hline Head width (HW) & 16.0 & $10.3-19.5$ & 15.8 & $10.7-15.0$ & 19.5 & 14.8 \\
\hline Snout length (ES) & 9.4 & $7.2-11.5$ & 8.2 & $6.5-8.6$ & 11.5 & 9.6 \\
\hline Orbit diameter (ED) & 4.5 & $4.6-8.2$ & 5.3 & $5.0-6.8$ & 8.2 & 7.0 \\
\hline Tympanum-eye (TYE) & 7.0 & $4.8-8.5$ & 5.3 & $4.3-6.0$ & 8.5 & 7.7 \\
\hline Axilla-groin length (AG) & 51.2 & - & 47.3 & - & 63.7 & 43.3 \\
\hline Thigh length (FEL) & 16.4 & $11.7-19.9$ & 17.3 & $10.2-19.3$ & 18.1 & 17.7 \\
\hline Shank length (TBL) & 15.8 & $11.6-21.2$ & 15.4 & $13.3-19.6$ & 21.2 & 17.9 \\
\hline Midbody scale rows & 33 & $32-34$ & 28 & $28-30$ & 38 & 36 \\
\hline Paravertebral scales & 45 & $42-46$ & 33 & $32-35$ & 53 & 52 \\
\hline Ventrals & 55 & $55-59$ & 48 & $48-52$ & 70 & 65 \\
\hline Lamellae on $4^{\text {th }}$ toe & 18 & $18-20$ & 21 & $19-21$ & 20 & 21 \\
\hline
\end{tabular}

Table 3. Diagnostic characters of Eutropis macrophthalma, E. multifasciata, E. rudis, E. lewisi, and E. dattaroyi sp. nov.; modified after Amarasinghe et al. (2018).

\begin{tabular}{|c|c|c|c|c|c|}
\hline & 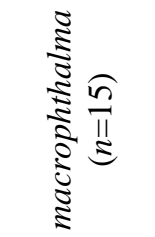 & 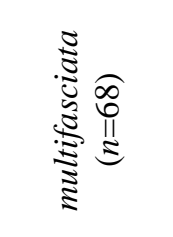 & 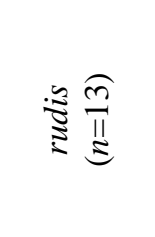 & 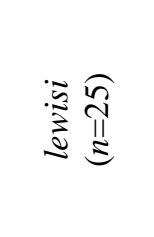 & 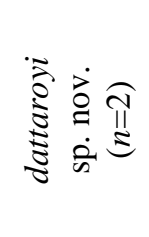 \\
\hline Paravertebral scales & $35-38$ & $43-48$ & $42-46$ & $32-35$ & 52,53 \\
\hline Ventrals & $49-52$ & $53-58$ & $55-59$ & $48-52$ & $65-70$ \\
\hline Subdigital lamellae of $4^{\text {th }}$ toe & $21-24$ & $16-19$ & $18-20$ & $19-21$ & 20,21 \\
\hline Midbody scale rows & $24-26$ & $32-34$ & $32-34$ & $28-30$ & $36-38$ \\
\hline Supralabials (touch orbit) & $7(6)$ & $6(5)$ & $6(5)$ & $6(5)$ & $7(5)$ \\
\hline Dorsal surface of thigh smooth $(0)$, keeled $(1)$ & 1 & 0 & 1 & 1 & 1 \\
\hline Temporal scales smooth $(0)$, keeled (1) & 1 & 0 & 1 & 1 & 0 \\
\hline Lateral band invisible $(0)$, visible (1) & 1 & 1 & 1 & 0 or 1 & 0 \\
\hline Rostral dorsally indistinct (0), distinct (1) & 1 & 1 & 0 & 1 & 1 \\
\hline Number of supraoculars touching the frontal & $2^{\text {nd }}$ & $2^{\text {nd }}$ & $1^{\text {st }} \& 2^{\text {nd }}$ & $2^{\text {nd }}$ & $2^{\text {nd }}$ \\
\hline ES / SVL\% & $8.5-9.8 \%$ & $9.1-10.0 \%$ & $7.7-9.0 \%$ & $8.0-9.4 \%$ & $9.3-9.7 \%$ \\
\hline $\begin{array}{l}\text { Average SVL } \\
\text { (maximum SVL) in } \mathrm{mm}\end{array}$ & $\begin{array}{c}128.0 \\
(136.4)\end{array}$ & $\begin{array}{c}95.8 \\
(120.8)\end{array}$ & $\begin{array}{c}92.0 \\
(123.1)\end{array}$ & $\begin{array}{c}87.3 \\
(98.6)\end{array}$ & $\begin{array}{c}111.2 \\
(123.1)\end{array}$ \\
\hline Type locality & Sulawesi & Java & Sumatra & Borneo & $\begin{array}{c}\text { Great } \\
\text { Nicobar }\end{array}$ \\
\hline
\end{tabular}




\section{Plate 07}

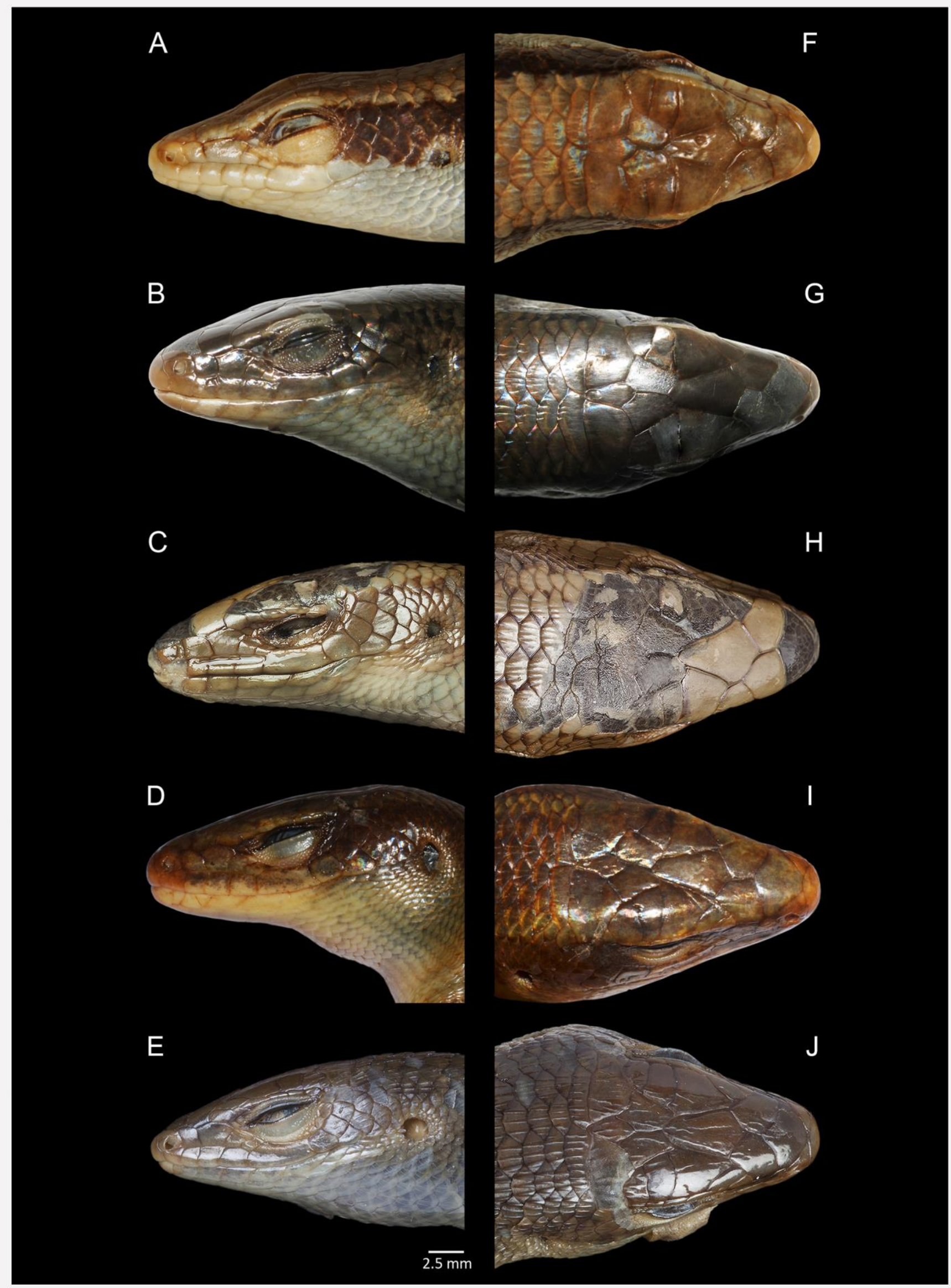

Figure 7. Head in lateral and dorsal views of (A, F) holotype of Eutropis macrophthalma (ZFMK 71717); (B, G) neotype of E. multifasciata (MZB 11912); (C, H) lectotype of E. rudis (BMNH 1946.8.15.26); (D, I) holotype of Eutropis dattaroyi sp. nov. (ZSI 25118); (E, J) lectotype of E. lewisi (BMNH 1946.8.3.57); modified after Amarasinghe et al. 2018 


\section{Plate 08}

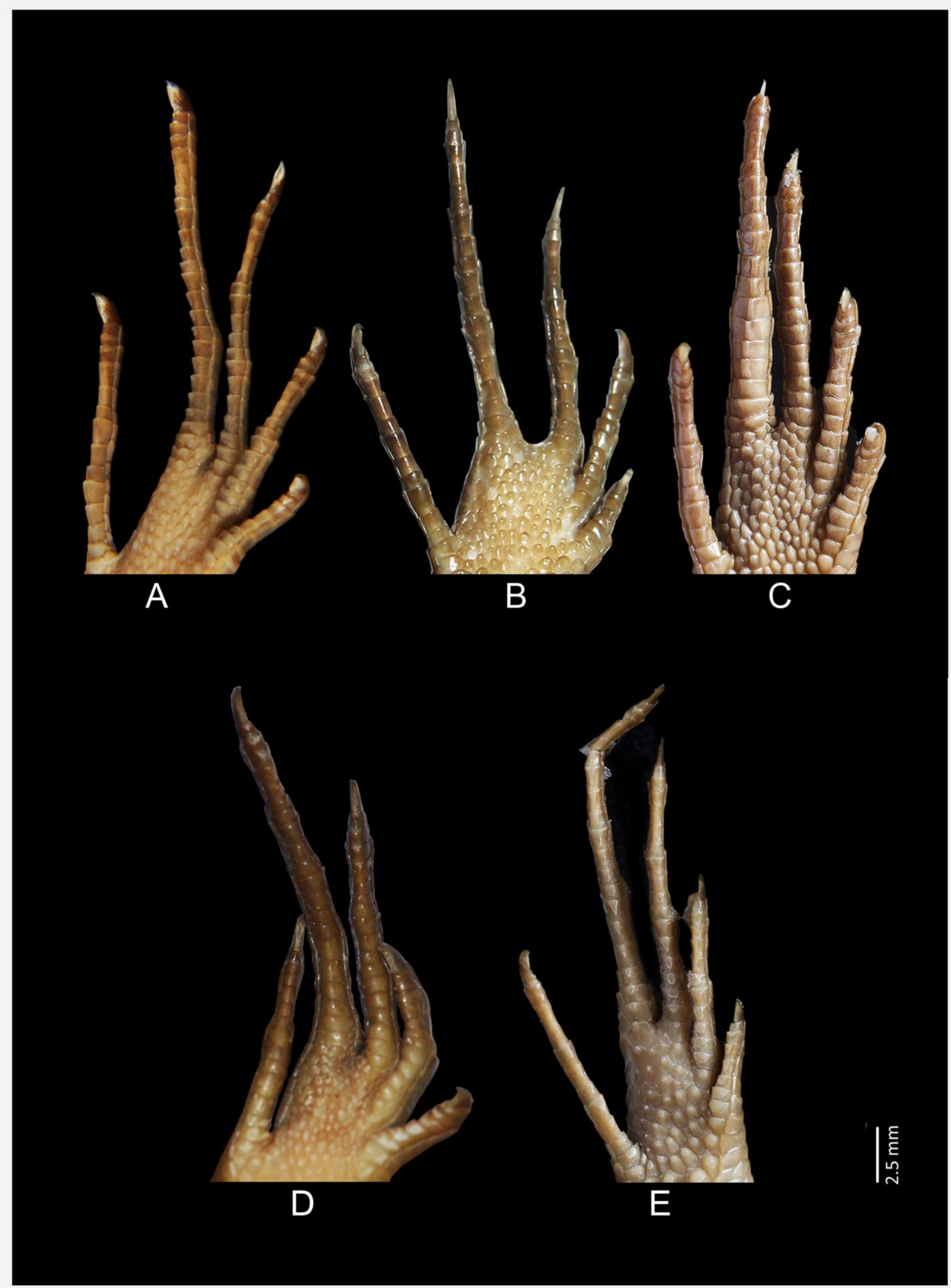

Figure 8. Subdigital lamellae of (A) holotype of Eutropis macrophthalma (ZFMK 71717); (B) neotype of E. multifasciata (MZB 11912); (C) lectotype of E. rudis (BMNH 1946.8.15.26); (D) holotype of E. dattaroyi sp. nov. (ZSI 25118); (E) lectotype of E. lewisi (BMNH 1946.8.3.57); modified after Amarasinghe et al. 2018 


\section{Discussion}

Mabuia rudis was described based on six specimens; one adult collected from Sumatra, Indonesia and five juveniles collected from Matang, Sarawak, Borneo. The Sumatran specimen, BMNH 1946.8.15.26 has been designated here as a lectotype of Mabuia rudis. This lectotype was collected by Carl Alfred Bock (1849-1932), a Norwegian explorer who travelled to Batavia (Jakarta, see Amarasinghe et al. 2015: 36), Indonesia in 1878 to undertake a bird-collecting trip to Sumatra (Reece 1995; King 1995). He travelled to Padang in West Sumatra before returning to Batavia in June 1879. He sent his collections to London in two shipments; the first arrived safely and the second shipment was unfortunately lost when the ship carrying the container sunk in the Red Sea (Reece 1995, King 1995). Following this, Bock was then charged with undertaking an expedition to Borneo for which he subsequently set sail; the lectotype at the Natural History Museum, UK had been received by the museum prior to Bock's expedition in Borneo. It is therefore highly likely that the lectotype of Mabuia rudis was collected from around the vicinity of Padang. We therefore, restrict the type locality of $M$. rudis to West Sumatra, Indonesia.

The other paralectotypes of $M$. rudis were purchased from Mr. Cutter, a natural history dealer in Bloomsbury, London. Considering the locality records of Eutropis rudis, it seems that this species is widely distributed, perhaps with a similar distribution pattern to that of $E$. multifasciata (see Amarasinghe et al. 2018). It is speculated that a sub-population of $E$. rudis from the island of Borneo may have evolved as the distinct species for which we resurrect the name E. lewisi. It seems that E. lewisi is a Bornean endemic which is distributed in low elevations, evidently in north-western (Sarawak) and eastern (East Kalimantan) parts of the island.

Smith (1935) included the Nicobar Islands in the distribution range of Mabuya multifasciata multifasciata and remarked that this species is replaced in Borneo by $M . m$. rudis. Eutropis rudis itself was reported apparently for the first time from Great Nicobar Island of the Nicobar archipelago by Biswas \& Sanyal (1980). Later, Biswas (1984) recorded $E$. rudis from Campbell Bay in Great Nicobar and mentioned some diagnostic morphological characters to distinguish it from E. multifasciata which occurs in sympatry. Subsequently, Das
(1994, 1999), Vijayakumar (2005), and Harikrishnan et al. (2014) listed E. rudis in their lists of herpetofauna from the Nicobar Islands. The taxonomic status of this population has not been scrutinized rigorously until now.

The redefinition of $E$. rudis based on its lectotype designated here has enabled us to recognize the precise and consistent, geographically correlated morphological variations between these populations which have now been defined as distinct species. The Nicobar archipelago is separated from the Great Sundaic Island of Sumatra by the Great Channel which acts as an effective biogeographic barrier, limiting the distribution of several herpetofaunal taxa such as Boiga wallachi Das, 1998; Bronchocela danieli (Tiwari \& Biswas, 1973); and Dendrelaphis humayuni Tiwari \& Biswas, 1973. All of these species are restricted to the Nicobar archipelago and do not cross the Great Channel. That also appears to be the case with the new species $E$. dattaroyi described here: $E$. rudis occupies the Burmese peninsula to the north of its range and ranges to Sumatra, Java and Borneo to the southeast of its range. Within this species group, E. rudis co-occurs with $E$. lewisi on Borneo and E. multifasciata in other regions, whereas $E$. dattaroyi sp. nov. co-occurs with the Great Nicobarese population of $E$. cf. multifasciata. The description of $E$. dattaroyi sp. nov. has raised the number of endemic skinks in the Nicobar Islands to four, the others being Dasia nicobarensis Biswas \& Sanyal, 1977; Lipinia macrotympanum (Stoliczka, 1873) (also known from the Andaman Islands); and Scincella macrotis (Steindachner, 1867).

Key to the species of the Eutropis rudis complex (modified after Amarasinghe et al. 2018). The current distribution of each species is indicated in Figure 9.

1. (a) Dorsal surface of thigh and temporal region smooth, 43-48 paravertebrals, 53-58 ventrals, 16-19 lamellae on $4^{\text {th }}$ toe, 32-34 midbody scale rows ....................................... multifasciata

(b) Dorsal surface of thigh keeled ...................... 2

2. (a) 24-30 midbody scale rows, 48-52 ventrals, 32-38 paravertebral scales ............................... 3

(b) 32-38 midbody scale rows, 55-70 ventrals, 42-53 paravertebral scales ................................. 4

3. (a) 24-26 midbody scale rows, lateral band on the body present, 35-38 paravertebral scales, 21-24 subdigital lamellae on $4^{\text {th }}$ toe .... E. macrophthalma 
(b) 28-30 midbody scale rows, lateral band on the body absent, 32-35 paravertebral scales, 19-21 subdigital lamellae on $4^{\text {th }}$ toe

E. lewisi

4. (a) 32-34 midbody scale rows, dark upper lateral zone present on body, 42-46 paravertebral scales, scales on temporal region keeled, 55-59 ventrals, $18-20$ subdigital lamellae on $4^{\text {th }}$ toe ........ E. rudis

(b) 36-38 midbody scale rows, upper lateral region of body not differently coloured to lateral and dorsal body, 52 or 53 paravertebral scales, scales on temporal region smooth, 65-70 ventrals, 20 or 21 subdigital lamellae on $4^{\text {th }}$ toe

E. dattaroyi sp. nov.

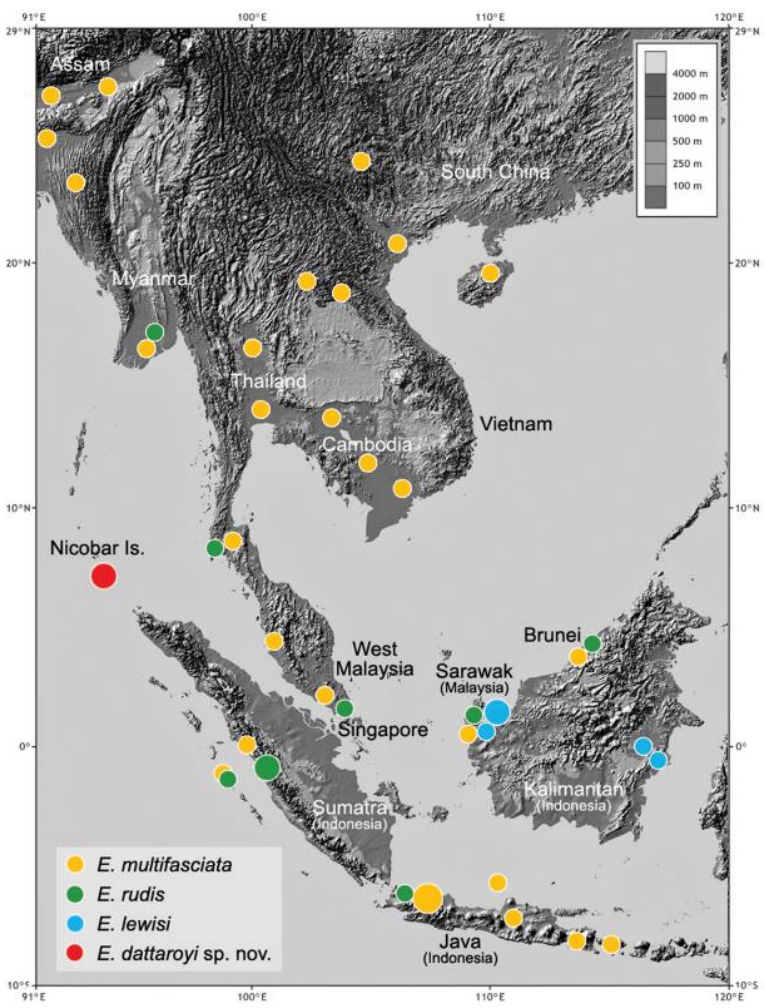

Figure 9. Current distribution of Eutropis multifasciata (yellow), E. rudis (green), E. lewisi (blue), and E. dattaroyi sp. nov. (red) in Sundaland, based on examined specimens; the larger circles represent the type locality of respective species.

\section{Acknowledgments}

We thank the Ministry of Research and Technology of the Republic of Indonesia for granting research permits to AATA; we also thank the former Director, K. Venkataraman (ZSI) for granting research permission to AATA. In particular we thank K. Chandra (Director, ZSI) K. C. Gopi (ZSI), K. A. Subramanian (ZSI) for their help throughout the permitting application process. S. Raha, P.G.S. Sethy, P. Bag, and S. Debnath are also acknowledged for assisting us while examining collections in ZSI. K.V. Devi Prasad (Pondicherry University) and the Department of Environment and Forests, Andaman and Nicobar Islands (Government of India) are acknowledged for the support extended. In addition $\mathrm{R}$. Ubaidillah, A. Hamidy, A. Riyanto, Syaripudin, W. Trilaksana and other staff members of MZB are acknowledged for facilitating the in-house study of specimens under their care. We thank S.S. Mishra for providing some literature and A. Chaudhuri for taking photos of the holotype of the new species. We thank Jakob Hallermann (Universität Hamburg, Germany), Glenn Shea (University of Sydney, Australia), Salvador Carranza (Institute of Evolutionary Biology, Barcelona, Spain), and Olivier S.G. Pauwels (Royal Belgian Institute of Natural Sciences, Brussels) for the review of the manuscript and critical comments. SK thanks P. Antony, K. Gunawardena and V. Weeratunga for the travel grant to visit ZSI (India). SRC thanks the Mohamed bin Zayed Species Conservation Fund (Grant No: 160514249) which facilitated fieldwork in the Nicobar Islands. Finally, we thank J. Supriatna and the staff of the Research Center for Climate Change, University of Indonesia, for their support.

\section{Literature Cited}

Amarasinghe, A.A.T., P.D. Campbell, J. Hallermann, I. Sidik, J. Supriatna et al. (2015). Two new species of the genus Cylindrophis Wagler, 1828 (Squamata: Cylindrophiidae) from Southeast Asia. Amphibian and Reptile Conservation 9 (1): 34-51.

Amarasinghe, A.A.T., N.A. Poyarkov Jr., P.D. Campbell, S. Leo, J. Supriatna et al. (2017). Systematics of Eutropis rugifera (Stoliczka, 1870) (Squamata: Scincidae) including the redescription of the holotype. Zootaxa, 4272 (1): 103-118.

Amarasinghe, A.A.T., P. Thammachoti, P.D. Campbell, J. Hallermann, S.M. Henkanaththegedara et al. (2018). Systematic composition of the Eutropis multifasciata (Kuhl, 1820) species complex (Squamata: Scincidae) and designation of a neotype. Herpetologica, 74 (4): 342-354.

Bartlett, E. (1895). The crocodiles and lizards of Borneo in the Sarawak Museum, with descriptions of supposed new species, and the variation of colours in the several species during life. Journal of the Straits Branch Royal Asiatic Society Singapore, 28: 73-96.

Biswas, S. (1984). Some notes on the reptiles of the Andaman and Nicobar Islands. Journal of 
the Bombay Natural History Society, 81 (2): 476-481.

Biswas, S. and D.P. Sanyal (1980). A report on the reptilian fauna of Andaman and Nicobars Islands in the collection of Zoological Survey of India. Records of the Zoological Survey of India, 77: 255-292.

Boulenger, G.A. (1887). Catalogue of the Lizards in the British Museum (Nat. Hist.) III. Lacertidae, Gerrhosauridae, Scincidae, Anelytropsidae, Dibamidae, Chamaeleontidae, London: $575 \mathrm{pp}$.

Brown, W.C. and A.C. Alcala (1980). Philippine Lizards of the family Scincidae. Silliman University, Natural Sciences, Dumaguete City, Monograph series, 2: $246 \mathrm{pp}$.

Das, I. (1994). A check-list of the amphibians and reptiles of Andaman and Nicobar Islands. Journal of the Andaman Science Association, 10 (1\&2): 44-49.

Das, I. (1999). Biogeography of the amphibians and reptiles of the Andaman and Nicobar Islands, India. In: Ota, H. (ed.) Tropical Island herpetofauna: origin, current diversity and current status. Elsevier: 43-77.

Harikriahnan, S., K. Vasudevan, A. Das, B.C. Choudhury, S.K. Dutta et al. (2014). Macroecology of Terrestrial Herpetofauna in Andaman \& Nicobar Archipelago. Report: Wildlife Institute of India: 49 pp.

Howard, S.D., G.R. Gillespie, A. Riyanto, and D. Iskandar (2007). A new species of large Eutropis (Scincidae) from Sulawesi, Indonesia. Journal of Herpetology, 41 (4): 604-610.
King, V.T. (ed). (1995). Explorers of South-East Asia: Six Lives. Kuala Lumpur, Oxford University Press, London.

Kuhl, H. (1820). Beiträge zur Zoologie und vergleichenden Anatomie. Hermannsche Buchhandlung, Frankfurt, 152 pp.

McCune, B. and J.B. Grace (2002). Analysis of Ecological Communities. MjM Software Design, USA.

Mausfeld, P. and W. Böhme (2002). A new Mabuya from Java, Indonesia. Salamandra, 38 (3): 135-144.

Oksanen, J., F.G. Blanchet, R. Kindt, and H. Wagner (2012). Vegan: Community Ecology Package, R package version 2.0-4. Available at www.CRAN.R-project.org.

Reece, B. (1995). Carl Bock (1849-1932): Explorations and travels in Sumatra, Borneo, and Siam. In: King, V.T. (ed.), Explorers of South-East Asia: Six Lives: 194-228.

Smith, M.A. (1935). The fauna of British India, including Ceylon and Burma. Reptiles and Amphibia, Vol. II. Sauria. Taylor and Francis, London: 440 pp.

Uetz, P., S. Cherikh, G. Shea, I. Ineich, P.D. Campbell et al. (2019). A global catalog of primary reptile type specimens. Zootaxa, 4695 (5): 438-450.

Vijayakumar, S.P. (2005). Status and distribution of Amphibians and Reptiles of the Nicobar Islands, India. Final Report. Rufford Foundation / Madras Crocodile Bank / Wildlife Institute of India: $48 \mathrm{pp}$.

Appendix I. Other specimens Examined

Eutropis lewisi (25 ex.): Borneo: BMNH 1946.8.3.57 (lectotype), 1946.9.7.47-50 (paralectotype of Mabuia rudis); Kalimantan, Indonesia: MZB 2937, 9521-23, 13224, 13227-8, 13231-2, 13236-39; Borneo: ZSI 15155, 15160-62, 15328, 15346, 20323.

E. macrophthalma (15 ex.): Java (in error), Indonesia: ZFMK 71717 (holotype), ZFMK 71716 (paratype); Sulawesi, Indonesia: MZB 3870-73, 4313-4, 4316-7, 4319, 4321-2 (paratypes of E. grandis), MZB $1781,7785$.

E. multifasciata (71 ex.): Bali, Indonesia: SMF 22087 (type of Mabuya multifasciata baliensis), MZB 2042, 2100, 8739; Java, Indonesia: MZB 11912 (neotype), 289, 552, 651, 715, 746, 748, 765, 772, 854, 914, 11912-16, 1477, 1495, 1510, 2168, 2170, 2368, 8431, 9419; Karimunjawa, Indonesia: SMF 55147 (type of Mabuya multifasciata tjendikianensis) Sumatra, Indonesia: MZB 1921; Lesser Sunda Islands, Indonesia: MZB 10255; Penang, Malaysia: ZSI 2275-77, 2279-80; Thailand: ZSI 18071, 18120-1; Myanmar: ZSI 2307, 4633, 4876-79, 11750-1, 12630, 12735, 12835-6, 16731; Assam, India: ZSI 2285-6, 2288, 2306, 2309, 4007, 4625-27, 11416-7; Borneo: ZSI 15329, 15336-7; Indonesia: BMNH 1946.8.19.54 (type of Tropidolepisma macrurus); India: BMNH 1946.8.19.3 (type of Plestiodon sikkimensis), ZSI 2361-63 (type of Mabuya monticola).

E. rudis (13 ex.): Sumatra: BMNH 1946.8.15.26 (lectotype); Borneo: BMNH 1946.9.7.46 (paralectotype), ZSI 15330, 15332, 15344-5, 20323; Myanmar: ZSI 2307, 12680, 12735, 13474, 24795; Thailand: ZSI 18071.

E. tytleri (5 ex.): Andaman: ZSI 2273 (holotype), 2296, 2371, 4624; CSPT/L-33a. 
- blank page -

TAPROBANICA VOL. 09: NO. 01 